\title{
Talaromyces (Penicillium) marneffei and Mycobacterium tuberculosis coinfection in a HIV negative patient in Amritsar Punjab, India
}

\author{
Chalana M. ${ }^{1}$, Oberoi L. ${ }^{2}$ \\ ${ }^{1}$ Dr. Manvy Chalana, PG $3^{\text {rd }}$ Year, Microbiology, ${ }^{2}$ Dr. Loveena Oberoi, Professor \& Head, Department of Microbiology, \\ Government Medical College, Amritsar, Punjab, India.
}

Corresponding Author: Dr. Loveena Oberoi, Professor \& Head; Department of Microbiology, Government Medical College, Amritsar, Punjab, India. E-mail: loveenaoberoidr@gmail.com

\begin{abstract}
A 54-year-old, male patient with a history of Pulmonary Tuberculosis and Diabetes mellitus for the past 20 years was admitted to a tertiary care hospital with chief complaints of high-grade fever with chills, productive cough and a one month history of loss of appetite and generalized malaise. On FNAC of cervical lymph nodes; impression of tubercular pathology (AFB positive) was reported. Talaromyces (Penicillium) marneffei and Mycobacterium tuberculosis co-infection was confirmed. Talaromyces marneffei (Penicillium marneffei) is a thermally dimorphic fungus that can cause severe infections particularly in immunocompromised patients was first discovered in 1956 in the regions of Southeast Asia. It exists as mycelia form at $25{ }^{\circ} \mathrm{C}$ and yeast like form at $37^{\circ} \mathrm{C}$. A large number of T. marneffei infected patients who are HIV negative have been reported in recent years.
\end{abstract}

Key words: Talaromyces (Penicillium) marneffei, Mycobacterium tuberculosis, co infection

\section{Introduction}

Talaromyces marneffei (Penicillium marneffei) is a thermally dimorphic fungus that can cause severe infections particularly in immunocompromised patients was first discovered in 1956 in the regions of Southeast Asia [1,2]. The first report of human infection was reported by G. Segretain who accidentally pricked his finger with a needle containing the yeast cells of $P$. marneffei. A small nodule appeared at the site of infection followed by lymphangitis and lymphadenopathy 9 days after the accident [3]. There is no other species of this genus which is dimorphic in nature [4]. It exists as mycelia form at $25^{\circ} \mathrm{C}$ and yeast like form at $37^{\circ} \mathrm{C}$. Patients with HIV/AIDS have been reported to be vulnerable to T. marneffei. [5,6]. However, a large number of $T$. marneffei infected patients who are HIV negative have been reported in recent years [7,8,9]. 55 to $77 \%$ of cases may have other concurrent opportunistic infections such as tuberculosis, disseminated herpes zoster, Pneumocystis jiroveci pneumonia, cryptococcosis, toxoplasmosis and should be watched out for $[10,11,12]$.

\section{Case History}

A 54-year-old, male patient with a history of Pulmonary Tuberculosis and Diabetes mellitus for the past 20 years was admitted to a tertiary care hospital with chief complaints of high-grade fever with chills, productive cough and a one-month history of loss of appetite and generalized malaise. He had lost approximately $10 \mathrm{~kg}$ body weight in 2 months. He had a history of Pulmonary Tuberculosis infection diagnosed in 1999 but was not on treatment until 2013. Antitubercular therapy was subsequently initiated, but the patient had discontinued his medication 8 months prior. The patient was a known case of Diabetes Mellitus type 2 since the last 20 years and is on regular medication. His body temperature was $101.5^{\circ} \mathrm{F}$; blood pressure was 142/88 mmHg; pulse rate 86/minute; respiratory rate, 22/minute; and oxygen saturation,95\% in ambient air. On examination multiple cervical enlarged lymph nodes were palpated and hepatosplenomegaly was noted. The patient's laboratory test results

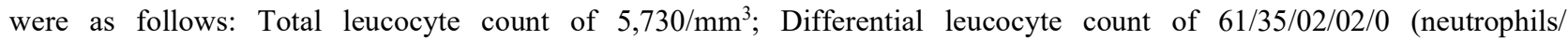
lymphocytes/monocytes/eosinophils/basophils); hemoglobin concentration $8.2 \mathrm{~g} / \mathrm{dL}$; platelet count $1.5 \mathrm{lakh} / \mathrm{mm}^{3}$. The glycosylated hemoglobin levels (HbA1C) was $0.9 \%$ indicating a fair to poor control of diabetes. The serum urea levels were $45 \mathrm{mg} / \mathrm{dl}$; serum creatinine levels were $1 \mathrm{mg} / \mathrm{dl}$, serum uric acid level was $6.5 \mathrm{mg} / \mathrm{dl}$; total serum bilirubin $0.73 \mathrm{mg} / \mathrm{dl}$,

Manuscript received: $26^{\text {th }}$ October 2019

Reviewed: $4^{\text {th }}$ November 2019

Author Corrected: $10^{\text {th }}$ November 2019

Accepted for Publication: 14 $4^{\text {th }}$ November 2019 
SGOT/SGPT OF 36/ $39 \mathrm{IU} / \mathrm{L}$. The serum sodium concentration $129 \mathrm{mmol} / \mathrm{L}$; and potassium concentration $3.7 \mathrm{mmol} / \mathrm{L}$. The fasting blood sugar level was $270 \mathrm{mg} / \mathrm{dl}$. On FNAC of cervical lymph nodes; impression of tubercular pathology (AFB positive) was reported. The HRCT chest revealed diffuse miliary nodules in both the lungs along with multiple patchy exudative shadows in the superior lobes and right inferior lobe, consolidation of the right superior lobe with multiple hilar and mediastinal lymphadenopathies. Sputum sample was collected in a clean wide mouth container under aspetic precautions for the isolation of respiratory pathogens, including mycobacteria and fungi. It was subjected for direct examination and for the culture. On $\mathrm{KOH}$ mount, no fungal elements were seen. Gram's stain shows yeast cells as gram positive oval cells. The sputum sample was inoculated on Sabouraud's dextrose agar (SDA) at $37^{\circ} \mathrm{C}$ and $22^{\circ} \mathrm{C}$. After ten days of incubation, SDA at $37^{\circ} \mathrm{C}$ showed no growth but SDA at $22^{\circ} \mathrm{C}$ showed yellowish green velvety colonies with brick red-coloured pigment on the reverse. Wet mount with Lactophenol cotton blue showed brush-like structures typical of the genus Penicillium, i.e., hyaline, septate hyphae with conidiophores with four to five short, broad metulae, each bearing four to six phialides with oval conidia. Subculture was done to demonstrate dimorphism. The fungus was inoculated on to Sabouraud's dextrose agar plate at $22^{\circ} \mathrm{C}$ and at $37^{\circ} \mathrm{C}$. Mycelial forms were seen at $22^{\circ} \mathrm{C}$ and yeast forms were seen at $37^{\circ} \mathrm{C}$. The isolate was identified as T. marneffei. The patient was started on Itraconazole $200 \mathrm{mg}$ twice daily.

\section{Discussion}

Talaromyces marneffei (formally Penicillium marneffei) is a thermally dimorphic and pathogenic fungus that is a major cause of morbidity and mortality among HIV positive and other immunocompromised patients who reside in, or travel to, regions where this fungus is endemic. T. marneffe $i$ is endemic to southern China, Taiwan, Hong Kong, and other parts of southeast Asia, particularly Northern Thailand, Vietnam, Cambodia, and northeastern India [13,14]. Prior to 2015 , T. marneffei was known as Penicillium marneffei.

The disease caused by $T$. marneffei was referred to as penicilliosis but is now called talaromycosis [15]. In recent years, it has been increasingly seen both in AIDS patients and in HIV-negative individuals. Among HIV negative patients with a history of pulmonary tuberculosis [16] or chronic obstructive pulmonary disease (COPD), $\mathrm{T}$. marneffei infection has been reported [17].

The main route of transmission of $\mathrm{T}$. marneffei is by inhalation; rarely is by direct animal contact. The typical clinical features are fever, weight loss, skin lesions, generalized lymphadenopathy, hepatosplenomegaly but the severity of the disease depends on the immune status of the patient.[18] The patient in this case was a male and nonHIV-infected patient but his lung immunity was probably impaired due to long-standing pulmonary tuberculosis.

The isolation of T. marneffei in HIV negative Patient is in consonance with a large multi-centric study done in Nanfang Hospital, Southern Medical University, Guangzhou, China for understanding of this disease and contribute to an appropriate regime of therapy.[19] A study conducted in Chiba University, Chiba, Japan showed a Disseminated Talaromyces (Penicillium) marneffei and Mycobacterium tuberculosis coinfection in a Japanese Patient with Acquired Immunodeficiency Syndrome [20]. Diagnosis of T. marneffei infection is made by visualization of the organism in clinical specimens by microscopy or by isolation of the organism on culture. The gold standard in diagnosis of talaromycosis is positive culture from appropriate clinical specimen. T. marneffe $i$ is a biohazard to laboratory staff [13] Slide cultures should not be performed; specimens and cultures should be handled in a biosafety level 3 containment or above [21].

Although methods have been developed for the detection of T. marneffei-specific antibodies and antigens, no standardized commercial serological assays are available.

Therefore, serology is not widely used for the diagnosis of T. marneffei infection $[13,14]$. Treatment with itraconazole alone has also been shown to be effective but is associated with higher relapse rate.

It has been suggested that itraconazole alone $400 \mathrm{mg} /$ day for 8 weeks could be considered for mild disease, followed by maintenance therapy with $200 \mathrm{mg}$ per day to prevent relapse [22].

\section{Conclusion}

In summary, our study reports a case of T. marneffei and M. tuberculosis coinfection in a HIV negative patient. This study invites clinicians to consider T. marneffei infection in non-HIV-infected patients with underlying diseases because early diagnosis and timely treatment can lead to reduction in the mortality associated with $T$. marneffei.

Funding: No funding sources

Conflict of interest: None declared

\section{Reference}

1. Capponi M, Sureau P, Segretain G. Penicillosis of Rhizomys sinensis. Bulletin de la Societe de pathologie exotique. 1956;49(3):418-421. 
2. Xiang Y, Guo W, Liang K. An unusual appearing skin lesion from Penicillium marneffei infection in an AIDS patient in central China. Am J Trop Med Hyg. 2015; 93(1):3. doi: 10.4269/ajtmh.14-0697.

3. Segretain G. [Penicillium marneffei n.sp., agent of a mycosis of the reticuloendothelial system]. Mycopathol Mycol Appl. 1959;11:327-353. doi: 10.1007/bf02089507.

4. Chander J. Talaromycosis. In A textbook of Medical Mycology. New Delhi: Mehta Publishers;2009;506-523.

5. Wang YF, Xu HF, Han ZG, Zeng L, Liang CY, Chen XJ, et al. Serological surveillance for Penicillium marneffei infection in HIV-infected patients during 2004-2011 in Guangzhou, China. Clin Microbiol Infect. 2015;21(5):484489. doi: 10.1016/j.cmi.2014.12.014. Epub 2014 Dec 26.

6. Wong SY, Wong KF. Penicillium marneffei Infection in AIDS. Pathol Res Int. 2011;2011. 764293. doi: 10.4061/ 2011/764293.

7. Duong TA. Infection due to Penicillium marneffei, an emerging pathogen: review of 155 reported cases. Clin Infect Dis. 1996;23(1):125-130. doi: https://doi.org/10. 1093 /clinids/23.1.125.

8. Liu GN, Huang JS, Zhong XN, Zhang JQ, Zou ZX, Yang ML,et al. Penicillium marneffei infection within an osteolytic lesion in an HIV-negative patient.Int J InfectDis. 2014; 23:1-3.doi:10.1016/j.ijid.2013.12.019.Epub2014 Mar 19

9. Qiu Y, Zhang J, Liu G, Zhong X, Deng J, He Z, et al. A case of Penicillium marneffei infection involving the main tracheal structure. BMC Infect Dis. 2014;14:242. doi: 10.1186/1471-2334-14-242.

10. Supparatpinyo K, Khamwan C, Baosoung V, Nelson KE, Sirisanthana T, Disseminated Penicillium marneffei infection in Southeast Asia. Lancet, 1994;344(8915):110113. doi: https://doi.org/10.1016/S0140-6736(94)91287-4.

11. Ranjana KH, Priyokumar K, Singh TJ, Gupta CC, Sharmila L, Singh PN, Chakrabarti A. Disseminated Penicillium marneffei infection among HIV-infected patients in Manipur state, India. J Infect. 2002;45(4):268271. doi: https://doi.org/10.1053/jinf.2002.1062.

12. Wu TC, Chan JWM, Ng CK, Tsang DNC, Lee MP, Li PCK. Clinical presentations and outcomes of Penicillium marneffei infections: a series from 1994 to 2004. Hong Kong Med J. 2008;14(2):103-109.
13. Chen SC, Sorrell TC, Meyer W. Aspergillus and Penicillium. Manual of clinical microbiology, 11th ed. ASM Press, Washington, DC. 2015, p 2030-2056.

14. Vanittanakom N, Cooper CR Jr, Fisher MC, Sirisanthana T. Penicillium marneffei infection and recent advances in the epidemiology and molecular biology aspects. Clin Microbiol Rev. 2006;19(1):95-110. doi: 10. 1128/ CMR.19.1.95-110.2006

15. Limper AH, Adenis A, Le T, Harrison TS. Fungal infections in HIV/AIDS. Lancet Infect Dis. 2017;17(11): e334-e343. doi: 10.1016/S1473-3099(17)30303-1. Epub 2017 Jul 31.

16. Wang PH, Wang HC, Liao CH. Disseminated Penicillium marneffei mimicking paradoxical response and relapse in a non-HIV patient with pulmonary tuberculosis. J Chin Med Assoc. 2015;78(4):258-260. doi: 10.1016/j. jcma.2013.11.009. Epub 2015 Mar 29.

17. De Monte A, Risso K, Normand AC, Boyer G, L'Ollivier C, Marty P, et al. Chronic pulmonary penicilliosis due to Penicillium marneffei: late presentation in a french traveler. J Travel Med. 2014;21(4):292-294. doi: 10. 1111/jtm.12125. Epub 2014 May 11.

18. DiSalvo AF, Fickling AM, Ajello L. Infection caused by Penicillium marneffei: description of first natural infection in man. Am J Clin Pathol. 1973;60(2):259-263. doi:https://doi.org/10.1093/ajcp/60.2.259.

19. Chi XH, Xue YM, Wang QS, Li GP, Zhou HS, Qi YS. Diagnosis and treatment of diffusible Penicillium marneffei in human immunodeficiency virus-negative patients: A challenge for the physician. Indian J Med Microbiol. 2017;35(4):617-619. doi: 10.4103/ijmm.IJMM_15_418.

20. Hu Y1, Zhang J, Li X, Yang Y, Zhang Y, Ma J, Xi L. Penicillium marneffei infection: an emerging disease in mainland China. Mycopathologia. 2013;175(1-2):57-67. doi: 10.1007/s11046-012-9577-0. Epub 2012 Sep 17.

21. Walsh T, Hayden RT, Larone DH. 2018. Talaromyces (Penicillium) marneffei. In Larone's medically important fungi: a guide to identification,6th ed. ASM Press, Washington, DC, p 176-177.

22. K. Supparatpinyo, P. Hirunsri, C. Uthammachai et al., An efficacy study of itraconazole in the treatment of Penicillium marneffei infection. J Med Assoc Thailand. 1992;75(12):688-691.

\section{How to cite this article?}

Chalana M, Oberoi L. Talaromyces (Penicillium) marneffei and Mycobacterium tuberculosis coinfection in a HIV negative patient in Amritsar Punjab, India. Trop J Path Micro 2019;5(11): 959-961.doi:10.17511/jopm.2019.i11.20 